\title{
Research Article Effect of Stress Corrosion on Relaxation of Large Diameter BGFRP Bars
}

\author{
Guowei Li $\mathbb{D}$, ${ }^{1}$ Sidi Kabba Bakarr $\mathbb{D},{ }^{1}$ Jingqiu Wang, ${ }^{2}$ Xue Liu, ${ }^{3}$ and Chengyu Hong $\mathbb{D}{ }^{4}$ \\ ${ }^{1}$ College of Civil and Transportation Engineering, Hohai University, Nanjing, 210098, China \\ ${ }^{2}$ Key Laboratory of Ministry of Education for Geomechanics and Embankment Engineering, Hohai University, Nanjing, 210098, China \\ ${ }^{3}$ Guangdong Nanyue Transportation Investment Construction Co., Ltd., Guangzhou, 510000, China \\ ${ }^{4}$ Department of Civil Engineering, Shanghai University, Shanghai, 200444, China
}

Correspondence should be addressed to Sidi Kabba Bakarr; skb2die4@yahoo.com

Received 10 August 2018; Accepted 29 October 2018; Published 2 December 2018

Academic Editor: Michael J. Schütze

Copyright (c) 2018 Guowei Li et al. This is an open access article distributed under the Creative Commons Attribution License, which permits unrestricted use, distribution, and reproduction in any medium, provided the original work is properly cited.

\begin{abstract}
Fibre reinforced polymer (FRP) rebars do not corrode like steel rebars when they are exposed to moisture such as water. Instead they have been shown to degrade when exposed to alkaline media and, in some cases, acids. It has especially demonstrated extensive deterioration when it has been simultaneously stressed and exposed to harsh environments. This combined effect has been termed as stress corrosion. The effect of stress corrosion on the stress relaxation of large sized prestressed basalt-glass fibre reinforced polymer (BGFRP) bars was analyzed by laboratory experiments. Two stressed bars were submerged in aqueous solutions of acid and alkaline in two separate plastic tanks under constant strain. Stress reduction values were observed over a period of about 7 months. Bars immersed in acid bath had an average stress relaxation of $9.2 \%$ and that in the alkali bath was observed to be about 13.4\%. These results support earlier assertions that exposure of GFRP bars to alkali media is likely to be detrimental to the long-term durability of the reinforced structure.
\end{abstract}

\section{Introduction}

Large diameter steel rods have been used as reinforcement in geotechnical engineering as soil nails and ground and rock anchors for slopes, tunnels, excavations, etc. for years. Steel reinforcement is susceptible to corrosion which is a major reason for the deterioration of these structures. Fibre reinforced polymer (FRP) bars have recently been identified as an ideal replacement for steel reinforcement because of their advantages of being environmentally friendly, lightweight, high stiffness, and being manufactured according to specific purposes compared with their steel counterparts. Toxic corrosion inhibitors have been used in the past to curb corrosion and these methods have been scrutinized by environmentalists as they are significant biohazards and pollutants [1]. FRP bars being environmentally friendly could be a way to minimise the use of these toxic corrosion inhibitors. FRP bars are known for their resistance to conventional corrosion that arises from exposure to moisture such as water and deicing salts as in the case of steel. This advantage is the main reason why FRP bars have been viewed as a promising alternative for steel structural reinforcement. Soil nails and anchors are mainly used under tension. Using a GFRP (glass fibre reinforced polymer) bar as a soil nail takes full advantage of its high tensile strength and avoids the disadvantages that come from its low shear modulus as a brittle material [2].

Stress corrosion has become a major focus in the field research of GFRP bars. This condition arises due to longterm loading combined with the effects of exposure to harsh environmental conditions such as acids, alkalis, and deicing salts which are major factors impacting the durability of this material. The most significant obstacle preventing the extended use of FRP materials is a lack of long-term and durability performance data compared to the data available for traditional construction materials [3]. Because the use of GFRP bars as soil nails depends on prestressing the rod, the knowledge of the extent of its stress relaxation capabilities becomes very important. High values of stress relaxation can lead to loss of tensile capacity to adequately reinforce the structure which could be detrimental to the durability of 
the system. Stress relaxation is one of the widely accepted test methods for predicting the long-term mechanical performance of structural materials and is time and cost efficient [4]. This paper illustrates the effects of the combination of stress and an aqueous environment on the stress relaxation of the GFRP bars. In these studies two GFRP rods are prestressed and submerged in a pool of acid and alkaline solutions each. The long-term use and durability of the bars as soil anchors are analyzed by observing stress relaxation values which are the primary parameters of measurement used in this study.

Over the years, some studies have been conducted regarding the time-dependent behaviour and long-term durability of GFRP bars [5-8]. These studies have contributed significantly to this area of study. Some of them cover the important phenomena of creep and recently few have covered the relaxation behaviour of GFRP rods [9-12]. Another limitation of these previous works is that a significant amount of the tests conducted was on small diameter GFRP bars (less than $20 \mathrm{~mm}$ ). In this study, we will investigate GFRP bars to be used as soil nail elements which often adopts larger geometric size bar, as that of steel soil nail elements (more than $25 \mathrm{~mm}$ of diameter), for use as slope construction reinforcement [13].

Exposure of ground anchors to subsurface moisture like water, acids, and alkali contribute significantly to the durability of ground anchors. Corrosion of steel reinforcement is the major cause of deterioration of existing reinforced concrete (RC) structures, resulting in significant expenses for repair and maintenance and leading to shorter service life. To address the corrosion problem, fibre reinforced polymer (FRP) bars have recently emerged as a promising solution not only in the rehabilitation of existing structures but also for the construction of new and more durable RC structures. But due to their versatile applications in harsh environments and exposure to high alkalinity content of concrete, the durability performance of FRP bars and their bond with concrete are major concerns [14].

Glass fibres are damaged due to the combination of two processes: (1) chemical attack on the glass fibres by an alkaline cement environment and (2) concentration and growth of hydration products between individual filaments [15]. The embrittlement of fibres is due to the nucleation of calcium hydroxide on the fibre surface. The hydroxylation can cause fibre surface pitting and roughening. These act as flaws severely reducing fibre properties in the presence of moisture. In addition, calcium, sodium, and potassium hydroxides found in the concrete pore solutions aggressively affect glass fibres. Therefore, the degradation of glass fibres is not only due to high $\mathrm{pH}$ level, but also due to the combination of alkalis and moisture. During the service life of a geotechnical system it is possible for the reinforcement to come into contact with acids due to acid rain or fluids attaining acidity when seeping through soil and collecting minerals. Acids are also known to seep through reinforced concrete and cause negative effects on traditional steel reinforcement $[16,17]$. Therefore, it is important to evaluate the effect an acidic environment might have on GFRP bars. The reaction rates of all these degradation phenomena increase with temperature [18].
Several authors have studied the effect of hazardous environments of the durability of fibre reinforced polymer composites [19-21], which included accelerated aging and combined effect of load and a simulated environment in acids, alkaline, salt water, etc. Nkurunziza et al. [22] critical review of the literature concerning the durability of GFRP reinforcing bars offers a substantial amount of useful information to the design engineer. The authors do a good job of explaining the degradation mechanism, listing the causes and advances in technology to combat the deterioration of GFRP bars used in reinforced concrete. In the concluding remarks, Nkurunziza et al. recognize that the durability tests cited in the review on the latest generation of GFRP bars subjected to stress higher than design limits, combined with aggressive mediums at elevated temperatures, have concluded that the strength reduction factors adopted by the current codes and guidelines are conservative. The factors adopted by the current codes and guidelines are based on few test results carried out on early generations of GFRP bars that have substantially evolved. Furthermore, accelerated testing techniques are very conservative and that tests more representative of actual field conditions are needed to accurately predict the long-term durability of the GFRP bars.

\section{Materials}

The following sections give descriptions of the materials used in the test.

2.1. Sand-Coated BGFRP Bars. The FRP bars used in this study are made of epoxy resin and two types of fibres including basalt and glass fibres. To improve the resistance of pure glass fibres composite to corrosion in alkaline environment, basalt-glass fibre hybrid composites with inner cores of glass fibre are covered by the basalt fibres with better alkali resistance. Physical properties of bars used are listed in Table 1.

As shown in Figure 1, the reinforcement materials used in the tests are the basalt-glass fibre hybrid composites with a diameter of $28 \mathrm{~mm}$ produced by Zhongshan Pulwell Composites Co., Ltd., in Guangdong Province, China, also used by the authors in [23]; body consists of a thermosetting epoxy resin and the contents of each component (by weight) are resin, $19 \%$, basalt fibre, $10 \%$, glass fibre, $65 \%$, and fine sand, $6 \%$.

2.2. Stress Relaxation Test Deformation Devices. If an FRP bar is loaded using traditional wedge-shaped frictional grips, the combination of high compressive stresses and mechanical damage caused by the serrations on the wedge surface will lead to premature failure of the grip zone. Griping the FRP bar with a device which could undertake the tensile load for any measurement of mechanical properties is a key technique. In this study, the seamless steel pipe was used to grip the FRP bar by filling it with binding agent which could expand by itself to gradually create compressive stresses. A centralizer was designed to keep the bar at the centre of the steel pipe for 


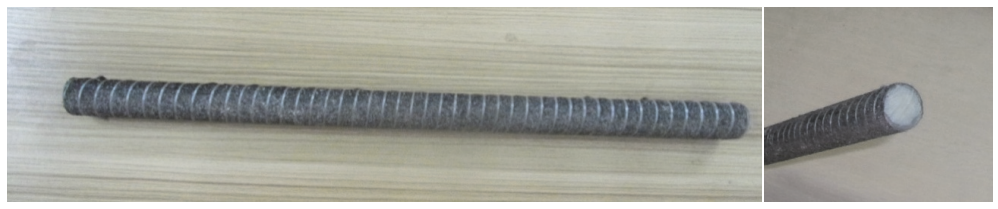

FIGURE 1: BGFRP bar specimen.

TABLE 1: Physical properties of FRP bars in study [23].

\begin{tabular}{|c|c|c|c|c|c|c|c|c|c|}
\hline \multicolumn{2}{|c|}{ Average Diameter (mm) } & \multirow{2}{*}{$\begin{array}{l}\text { Ratio of fibre weight of } \\
\text { basalt to total fibre (\%) }\end{array}$} & \multirow{2}{*}{$\begin{array}{l}\text { Density } \\
\left(\mathrm{g} / \mathrm{cm}^{3}\right)\end{array}$} & \multicolumn{4}{|c|}{ Content (weight ratio \%) } & \multicolumn{2}{|c|}{$\begin{array}{c}\text { Fibre volume fraction } \\
(\%)\end{array}$} \\
\hline Basalt & Glass & & & Basalt & Glass & Resin & Fine sand & Basalt & Glass \\
\hline 2.10 & 25.35 & 13.16 & 2.07 & 10 & 65 & 19 & 6 & 58.95 & 58.76 \\
\hline
\end{tabular}

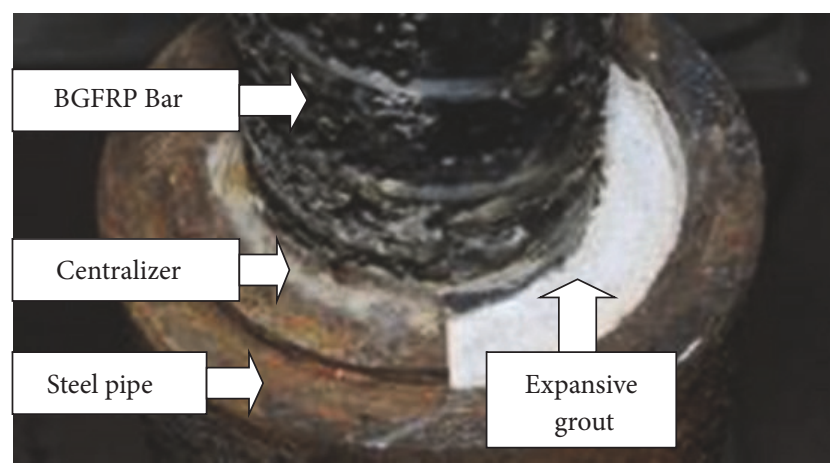

FIgURE 2: Diagram of centralizer keeping FRP bar central.

TABLE 2: FBG sensor positions.

\begin{tabular}{lc}
\hline Specimen Number & Sensor Position/cm \\
\hline 1 - Acidic $\mathrm{PH}=2$ & $0,19,34,49,68$ \\
2 - Alkaline $\mathrm{PH}=13$ & $0,19,34,49,69$ \\
\hline
\end{tabular}

the precise distribution of compressive stresses in the pipe as shown in Figure 2.

From the figure the white material shows the binding agent and half of the centralizer shown inserted into the gap. The first two half centralizers are fixed at one end of the pipe that is then inserted through the pipe until the other goes through the hole of the centralizers. The binding agent liquid made from cement, expansive material, and water is then poured into the pipe. The other two centralizers are fixed at the other end of the pipe and the specimen is left at room temperature and damp cured, by wrapping the sleeved ends with damp cloths and watering intermittently, for about 24 hours. The pipe at other end of the FRP rod was then filled with the binding material. Specimens were left to cure for another 24 hours and then fitted into the frames and left to properly cure at room temperature for not more than 15 days. The main advantage of this setup is that it can withstand a tensile stress that can reach $70 \%$ of its ultimate tensile strength for the large diameter FRP bar for the condition of constant deformation. This setup can satisfy the requirements of the durability test of FRP bars simulated to the actual carry processes of prestressed structures reinforced with FRP bar [23].

The loading system for the FRP bar relaxation test consisted of a hollow jack, steel casing with threaded support rods connecting outer screw nuts and connection to two bearing plates and bed plates, as shown in Figure 3.

Optic fibre Bragg grating (FBG) sensors were installed at the centre of the FRP bar body through $2 \mathrm{~mm}$ grooves and anchored by adhesive for the measurement of strain, as shown in Figure 5. Figure 4 shows the locations by distance of each sensor in the BGFRP bar.

Plastic rectangular immersion tanks were used to hold the acid and alkaline solutions. These tanks had holes through the smaller faces, through which the rods will pass as it is fixed on the frame and load applied as shown in Figure 6. Liquid $\mathrm{pH}$ values in the tanks were measured approximately, using litmus paper. Table 2 gives a precise description of the position of the sensors in the bar with the jack end of the rod being 0 .

\section{Experimental Procedure}

The deformation equipment is assembled and the tank is put into the frame. The rod specimens are inserted through the holes in the plates and walls of the plastic tanks. The holes in the plastic tanks are sealed with rubber and adhesive tape and injected with Vaseline to block gap between rubber and channel. The solutions are then poured into the tanks and engulf the free end of the specimens, with anchored sections hanging out either end of the setup.

The specimens undergo cyclic loading in a stepwise manner, each stage of loading increments of about $10 \mathrm{kN}$, with load cell values being recorded. At each stage of loading the regulatory load cell reading time rate of change is less than $2 \mathrm{kN} / \mathrm{h}$ as is standard. Load levels are read by the load cell; dial indicators on the faces of the smaller faces of the load plate give deformation readings. After this process is completed, the load is then increased and the step is repeated, until the bolt is loaded to $90 \mathrm{kN}$ and then locked to maintain strain and tension. The stressed specimens are then locked for about 7 days to allow for prestress loss to approach zero. 


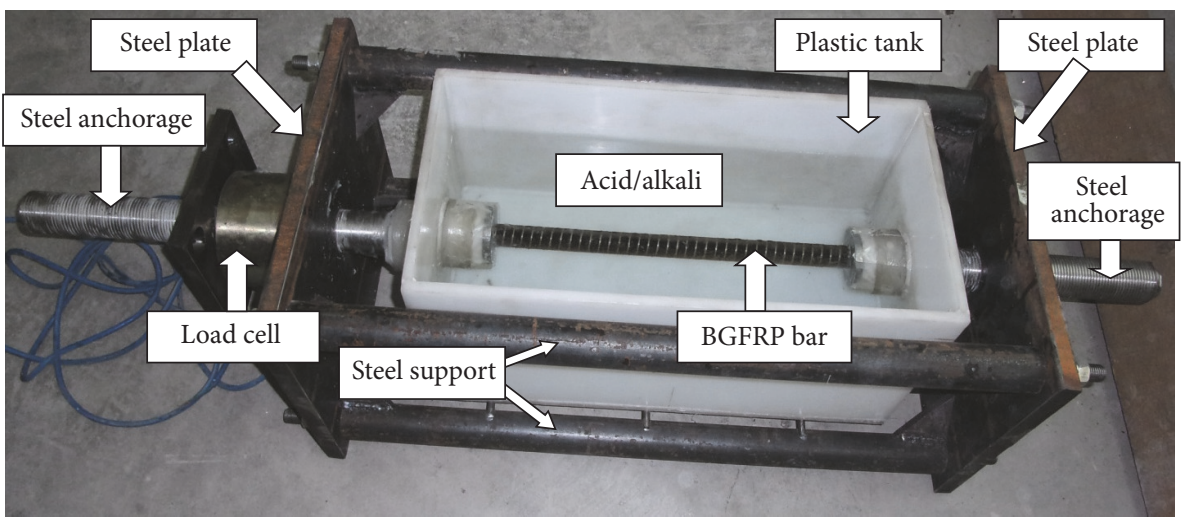

Figure 3: Photo of test apparatus.

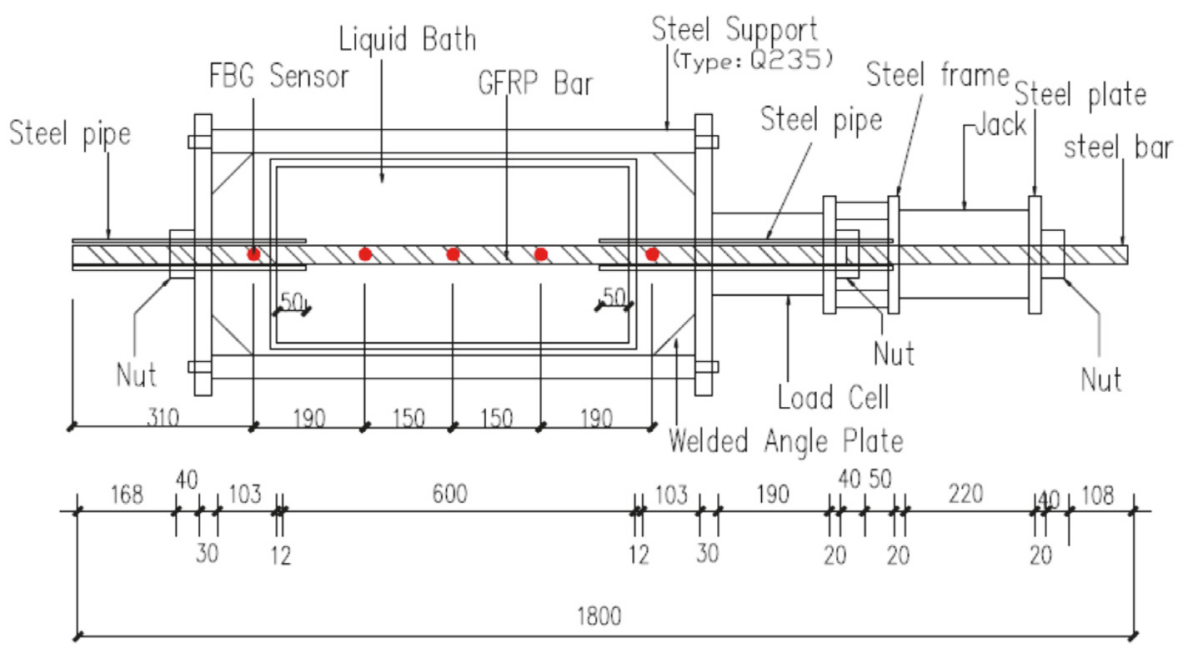

FIgURE 4: Detailed diagram of experimental setup.

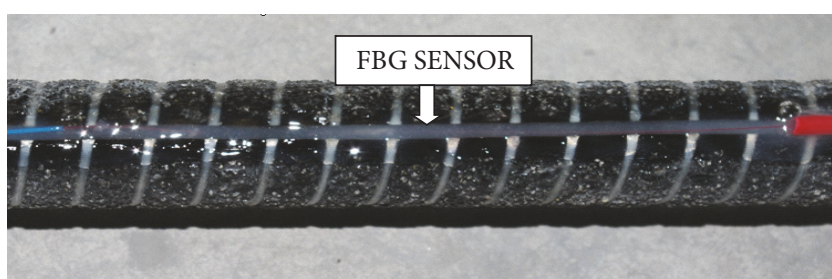

Figure 5: FBG sensor location on BGFRP bar.

Measurement and correlation of data starts after 10 days following the above procedure.

\section{Experimental Results and Analysis}

4.1. Stress Relaxation Analysis: Acid. The stress changes were recorded and analyzed for each sensor. From the trend shown in Figure 7, relaxation phenomenon is most prevalent in sensor 1 which relaxes from about 50 to 21MPa. Change in stress of sensors 2 and 3 was small from $135 \mathrm{MPa}$ and $148 \mathrm{MPa}$ to $122 \mathrm{MPa}$ and $134 \mathrm{MPa}$, respectively. This can be attributed to the distribution of stress in the specimen. Stress propagates from the loaded end of the rod to the other end and attempts to attain equilibrium. Hence the decrease in stress at the end anchorage points and that at the centre points are almost unchanged. Sensor 4 and sensor 5 were destroyed during stressing of the bar.

The average change in stress shown in Figure 7 is from FBG sensors 2 and 3. Individually they show relaxation percentages of 9.21 and $9.34 \%$, respectively, which shows the similarity of the relaxation process in that region of the bar. From the graph, change in stress was calculated to be 9.3\%, from $140 \mathrm{MPa}$ to about $128 \mathrm{MPa}$.

4.2. Stress Relaxation Analysis: Alkaline. Stress changes were analyzed in the alkaline engulfed specimen and the figures for each sensor reading are shown in Figure 8.

The most relaxation by percentage is seen to occur at the anchorage ends of the specimen and sensors 1 and 5 (from 85 and 58MPa to 49 and $34 \mathrm{MPa}$, respectively) as shown in Figure 8. Both curves showed a similar trend. Figure 8 shows the relaxation of the free central section of the rod 

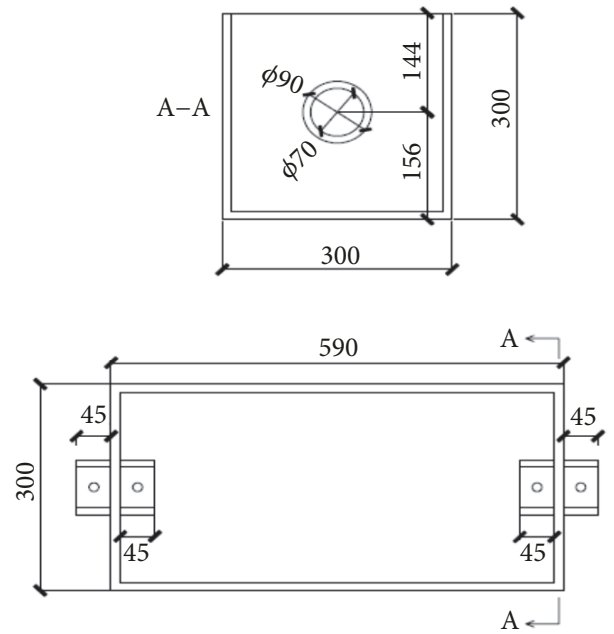

FIGURE 6: Diagram showing measurement of immersion tank.

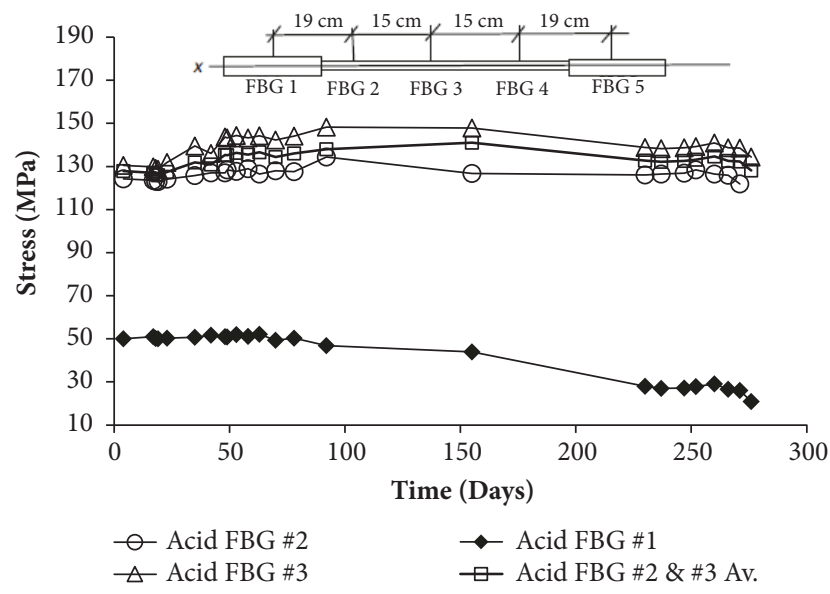

FIGURE 7: Stress versus time FBG sensors (acid).

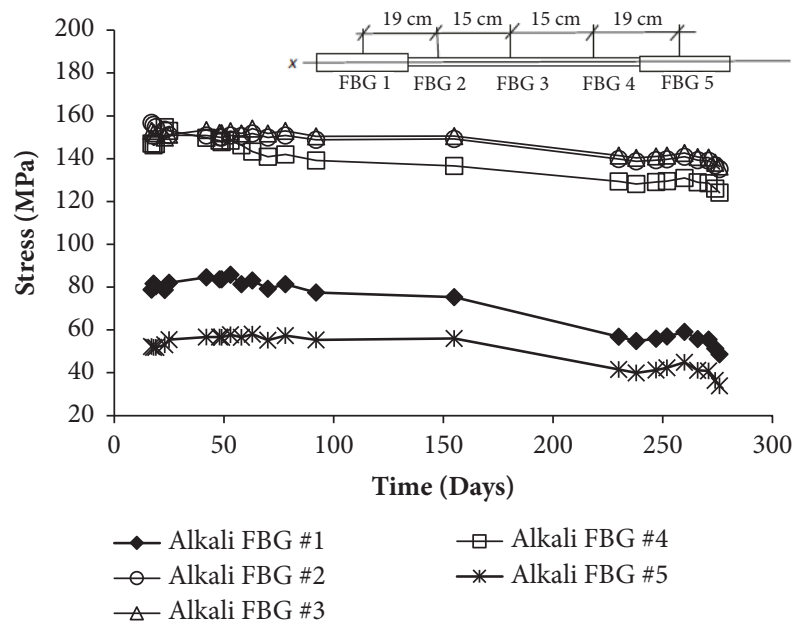

FIGURE 8: Stress versus time Alkali FBG sensors.

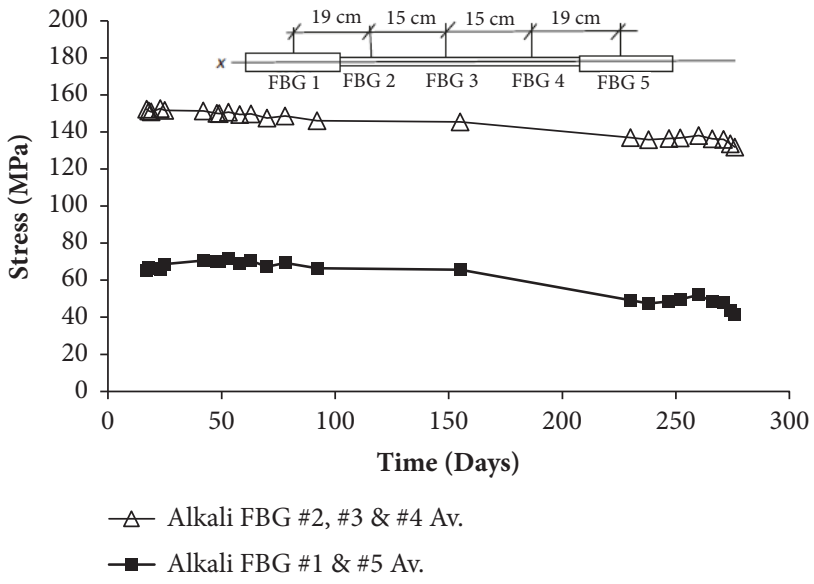

Figure 9: Stress versus time, average values (alkali).

monitored by sensors 2, 3, and 4 (from 156, 154, and 155MPa to 135,136 , and $124 \mathrm{MPa}$, respectively) showing similar curve trends revealing a consistent pattern for both sections of the specimen. This trend is attributed to the distribution of stress in the specimen. The average change in stress in the anchorage and free section were also plotted as shown in Figure 9. Stress value averages were calculated from FBG sensors 1 and 5 and sensors 2, 3, and 4. Average relaxation percentages for the anchorage section and free section were $42 \%$ and $13.7 \%$, respectively.

4.3. Combined Effect of Stress and Acidic/Alkaline Environment. Individually, a specimen exposed to a wet or corrosive environment and that exposed to a tensile force are both affected characteristically by the respective state. In this case, the specimens are both stressed and exposed to a hazardous environment. When these specimens are stressed, microcracks are expected to appear on the surface of the rod, thus facilitating the ingress of liquids into the bar, allowing it to penetrate the glass fibres. This only occurs if the axial force is high enough to cause microcracks. Nevertheless, the combined effect of sustained stress and a liquid or aqueous environment can lead to significant strength loss, interfacial degradation, and brittleness [24].

It is however important to note that the exposure of GFRP bars to acidic environments is not very prevalent in literature, as far as the author knows. Acids pose not as much a significant threat to the durability of the bars in itself. In combination with stress, the effects can lead to a penetration of the matrix by the acid, which will then unfavourably react with the fibres. Alkalis on their own have been known to have adverse effects on glass fibres and some types of matrices. In the case of our experiment, the synergistic effect of the acid/alkali and sustained stress must have been a factor in the stress relaxation observed in the test. Since the acid/alkali was in aqueous form and totally engulfed the specimen, this environment had an excess of highly mobile ions which is not usually the case in typical field conditions. Figure 10 shows the stress corrosion effect on relaxation, at room temperature, at a stress value of $90 \mathrm{kN}$. 


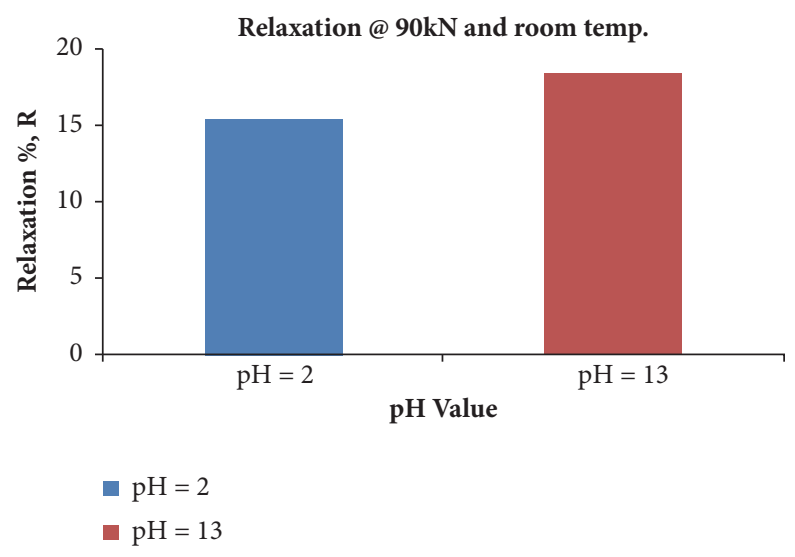

FIGURE 10: Combined effect of stress/load and environment on relaxation.

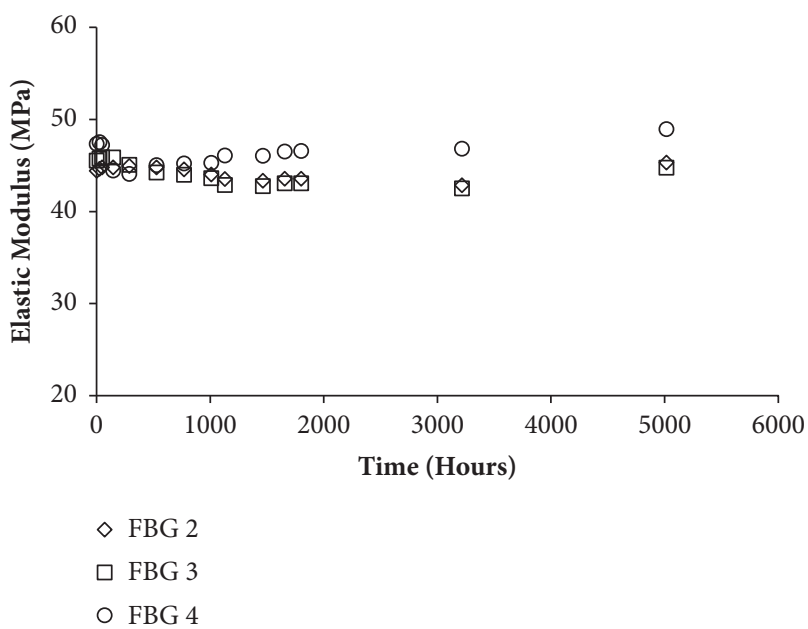

(a)

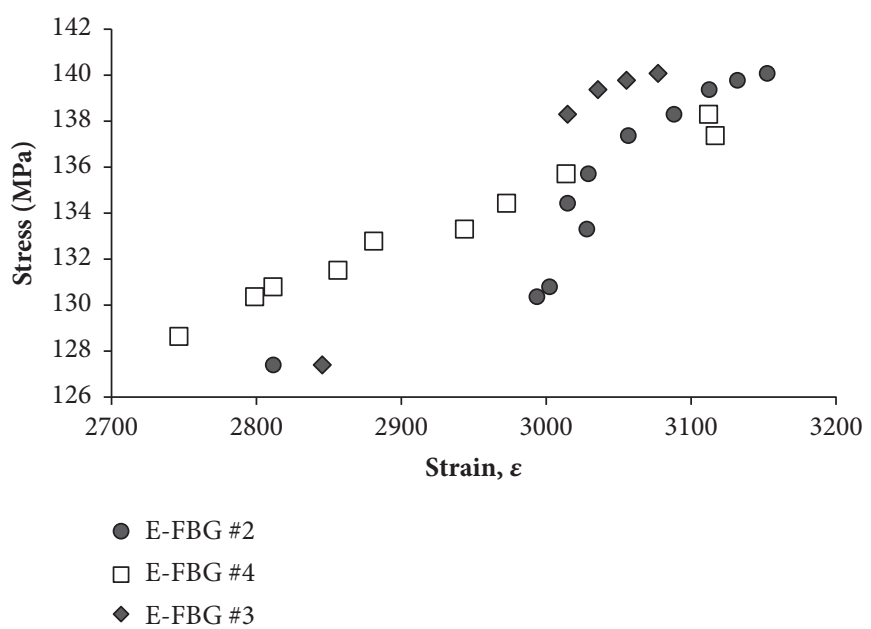

(b)

FIGURE 11: (a) Change in modulus versus time; (b) stress versus strain for FBG sensors.

Unfortunately other material parameters such as the residual tensile strength of the bar have not been conducted so all the conclusions arrived at are based on the stress relaxation. The tests were conducted at room temperature. More experiments of varying stress levels, $\mathrm{pH}$, and temperature have to be conducted to provide more data which can be analyzed to give better understanding of these conditions.

4.4. Anchorage Effect and Bar Rheological Properties. GFRP bars are part polymers and are expected to exhibit some amount of viscoelastic behaviour when subjected to longterm loading and various environmental conditions. Due to its rheological properties, the elastic modulus is a function of time, unlike in steel, which makes analysis of time-dependent deformation of FRPs more complex. An attempt was made at computing the elastic modulus during the experiment at the central regions of the acid specimen by obtaining stress values from load cell by dividing the load by the cross sectional area of the bar (see (1)), and calculating the changing elastic modulus as shown in (2):

$$
\begin{aligned}
\text { Stress, } \sigma & =\frac{\text { Load, } \mathrm{F}}{\text { Cross sectional area, A }} \\
\text { Elastic modulus, } \mathrm{E}(\mathrm{t}) & =\frac{\text { Stress, } \sigma}{\text { Strain, } \varepsilon}
\end{aligned}
$$

$\mathrm{E}(\mathrm{t})$ was plotted for the 3 central FBG sensors $(2,3$, and 4$)$ as shown in Figure 11.

It is observed from Figure 11(a) that the change in elastic modulus over the entire period of the experiment was very small, all within values from 42 to $49 \mathrm{MPa}$. This may mean that a large part of the relaxation was likely caused by more of the anchorage device's inability to properly restrain the specimen, deformations in the tensile frame setup, and the synergistic effect of the load and aqueous solutions, rather than the rheological properties of the bar itself. This 
phenomenon is also exhibited by the relatively linear stress versus strain curves as shown in Figure 11(b).

\section{Conclusions}

Two large diameter BGFRP bars were instrumented with FBG sensors, stressed to about $90 \mathrm{kN}$, each exposed to aqueous acid and alkali in plastic tanks. The aim was to observe the combined effect of tension and the simulated environment on the relaxation of the bars. From the analysis of data and test results and in consideration of experiment duration and conditions, the following conclusions were arrived at:

(a) As expected, relaxation is higher in the specimen submerged in alkali than that in the acid

(b) Results also show that even though acids are not as corrosive to FRP as alkalis are, it may still pose problems because of the high relaxation value obtained from the tests

(c) The test may also have exhibited high relaxation due to the ingress of the aqueous acid/alkali, especially in the case of the acid which may have needed help with entering the bars due to the cracks that may have propagated on the surface of the rod

(d) There was little change in the elastic modulus of the acid specimen which showed that a large part of the relaxation was due to the anchorage device's inability to properly restrain the bar, tensile frame deformation, and the simulated environment, rather than its rheological properties

(e) Further analysis of stress relaxation process is needed in the anchorage area to better understand the effect of the pressure exerted by the grout on the bar specimen

(f) Although the steel sleeve anchorage method has been proved to be effective, more tests should be done especially in the choice of grout used in anchorage for different applications. This may be done by testing different expansive agents within the steel sleeve and come up with better alternatives

The tests lasted for only 7 months. This time is not long enough to obtain the desired results since it takes some time for the liquids to diffuse into the specimen. Therefore, a longer test period would be recommended to get more accurate results. The tests also demonstrate relaxation with an excess amount of mobile ions in the aqueous environments and this overcompensates for actual field conditions. It would be useful for further tests that mimic actual field conditions to be conducted.

\section{Data Availability}

All data used is available and resides with corresponding author and can be provided by him upon request.

\section{Conflicts of Interest}

The authors declare that they have no conflicts of interest.

\section{Acknowledgments}

The authors would like to acknowledge the financial support provided by the National Natural Science Foundation of China (Project nos. 41472240 and 41602352), the Fundamental Research Funds for the Central Universities (Grant nos. 2015B25514 and 2015B17214), and the Government of Guangdong Province and Ministry of Education of China (Project no. 2009B09060011).

\section{References}

[1] A. A. Torres-Acosta, W. Martínez-Molina, and E. M. AlonsoGuzmán, "State of the Art on Cactus Additions in Alkaline Media as Corrosion Inhibitors," International Journal of Corrosion, vol. 2012, Article ID 646142, 9 pages, 2012.

[2] Z. Chen, L. Zheng, Q. Jin, and X. Li, "Durability study on glass fiber reinforced polymer soil nail via accelerated aging test and long-term field test," Polymer Composites, vol. 38, no. 12, pp. 2863-2873, 2017.

[3] A. Micelli and F. Nanni, "Mechanical Properties and Durability of FRP Rods," Center for Infrastructure Engineering Studies (CIES, University Missouri-Rolla, Rep. No.00-22 CIES), 2001.

[4] Y. J. Tong, L. H. Xu, and C. Q. Li, “The Stress Relaxation of Glass Fibre Composites With Low Velocity Impact Damage," in Proceedings of the Asia-Pacific Conference on FRP in Structures (APFIS 2007), S. T. Smith, Ed., International Institute for FRP in Construction, 2007.

[5] G. Nkurunziza, B. Benmokrane, A. S. Debaiky, and R. Masmoudi, "Effect of sustained load and environment on long-term tensile properties of glass fiber-reinforced polymer reinforcing bars," ACI Structural Journal, vol. 102, no. 4, pp. 615-621, 2005.

[6] F. Micelli, A. Nanni, and A. La Tegola, "Effects of Conditioning Environment on GFRP Bars," 22nd SAMPE Europe International Conference, CNIT Paris, March 27-29, 2001.

[7] R. Masmoudi, G. Nkurunziza, B. Benmokrane, and P. Cousin, "Durability of glass FRP composite bars for concrete structure reinforcement under tensile sustained load in wet and alkaline environments," in Proceedings of the Canadian Society for Civil Engineering - 31st Annual Conference: 2003 Building our Civilization, pp. 916-924, Canada, June 2003.

[8] Y. A. Al-Salloum and T. H. Almusallam, "Creep effect on the behavior of concrete beams reinforced with GFRP bars subjected to different environments," Construction and Building Materials, vol. 21, no. 7, pp. 1510-1519, 2007.

[9] I. Sasaki and I. Nishizaki, “Tensile Load Relaxation of Frp Cable System During Long-Term Exposure Tests," in Proceedings of theProceedings of the 6th International Conference on FRP Composites in Civil Engineering, CICE 2012, pp. 1-8, 2012.

[10] R. Sovjak, J. Fornusek, P. Konvalinka, and J. L. Vitek, "Creep and Stress Relaxation of Concrete Slab with Pre-stressed GFRP," in Proceedings of the 4th Asia-Pacific Conference on FRP in Structures, pp. 299-304, Seoul, Korea, 2009.

[11] G.-W. Li, C. Ni, H.-F. Pei, W.-M. Ge, and C. W. W. Ng, "Stress relaxation of grouted entirely large diameter B-GFRP soil nail," China Ocean Engineering, vol. 27, no. 4, pp. 495-508, 2013. 
[12] G.-W. Li, C.-Y. Hong, J. Dai et al., "FBG-Based Creep Analysis of GFRP Materials Embedded in Concrete," Mathematical Problems in Engineering, vol. 2013, Article ID 631216, 9 pages, 2013.

[13] H.-H. Zhu, J.-H. Yin, A. T. Yeung, and W. Jin, "Field pullout testing and performance evaluation of GFRP soil nails," Journal of Geotechnical and Geoenvironmental Engineering, vol. 137, no. 7, pp. 633-642, 2011.

[14] Y. Chen, "Accelerated ageing tests and long-term prediction models for durability of FRP bars in concrete," Dissertation submitted to the College of Engineering and Mineral Resources at West Virginia University 2007.

[15] V. M. Karbhari, K. Murphy, and S. Zhang, "Effect of concrete based alkali solutions on short-term durability of Eglass/vinylester composites," Journal of Composite Materials, vol. 36, no. 17, pp. 2101-2121, 2002.

[16] M. Criado, S. Fajardo, and J. M. Bastidas, "Corrosion Behaviour of a New Low-Nickel Stainless Steel Reinforcement: A Study in Simulated Pore Solutions and in Fly Ash Mortars," International Journal of Corrosion, vol. 2012, Article ID 847323, 8 pages, 2012.

[17] F. Yingfang, H. Zhiqiang, and L. Jianglin, "Ultrasonic Measurement of Corrosion Depth Development in Concrete Exposed to Acidic Environment," International Journal of Corrosion, vol. 2012, Article ID 749185, 8 pages, 2012.

[18] M. Robert, P. Wang, P. Cousin, and B. Benmokrane, “Temperature as an accelerating factor for long-term durability testing of FRPs: Should there be any limitations?" Journal of Composites for Construction, vol. 14, no. 4, pp. 361-367, 2010.

[19] S. Putic, M. Stamenovic, J. Petrovic, M. Rakin, and B. Medjo, "Effect of alkaline solutions on the tensile properties of glasspolyester pipes," Acta Periodica Technologica, no. 42, pp. 185195, 2011.

[20] F. E. Tannous and H. Saadatmanesh, "Environmental Effects on the Mechanical Properties of E-Glass FRP Rebars," ACI Materials Journal, vol. 95, no. 2, pp. 87-100, 1998.

[21] B. Benmokrane, P. Wang, T. M. Ton-That, H. Rahman, and J.F. Robert, "Durability of glass fiber-reinforced polymer reinforcing bars in concrete environment," Journal of Composites for Construction, vol. 6, no. 3, pp. 143-153, 2002.

[22] G. Nkurunziza, A. Debaiky, P. Cousin, and B. Benmokrane, "Durability of GFRP bars: A critical review of the literature," Progress in Structural Engineering and Materials, vol. 7, no. 4, pp. 194-209, 2005.

[23] L. Guo-wei, P. Hua-Fu, and H. Cheng-yu, "Study on the Stress Relaxation Behavior of Large Diameter B-GFRP Bars Using FBG Sensing Technology," International Journal of Distributed Sensor Networks, vol. 2013, Article ID 201767, 12 pages, 2013.

[24] G. Carra and V. Carvelli, "Ageing of pultruded glass fibre reinforced polymer composites exposed to combined environmental agents," Composite Structures, vol. 108, no. 1, pp. 10191026, 2014. 


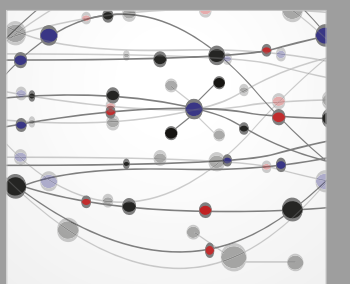

The Scientific World Journal
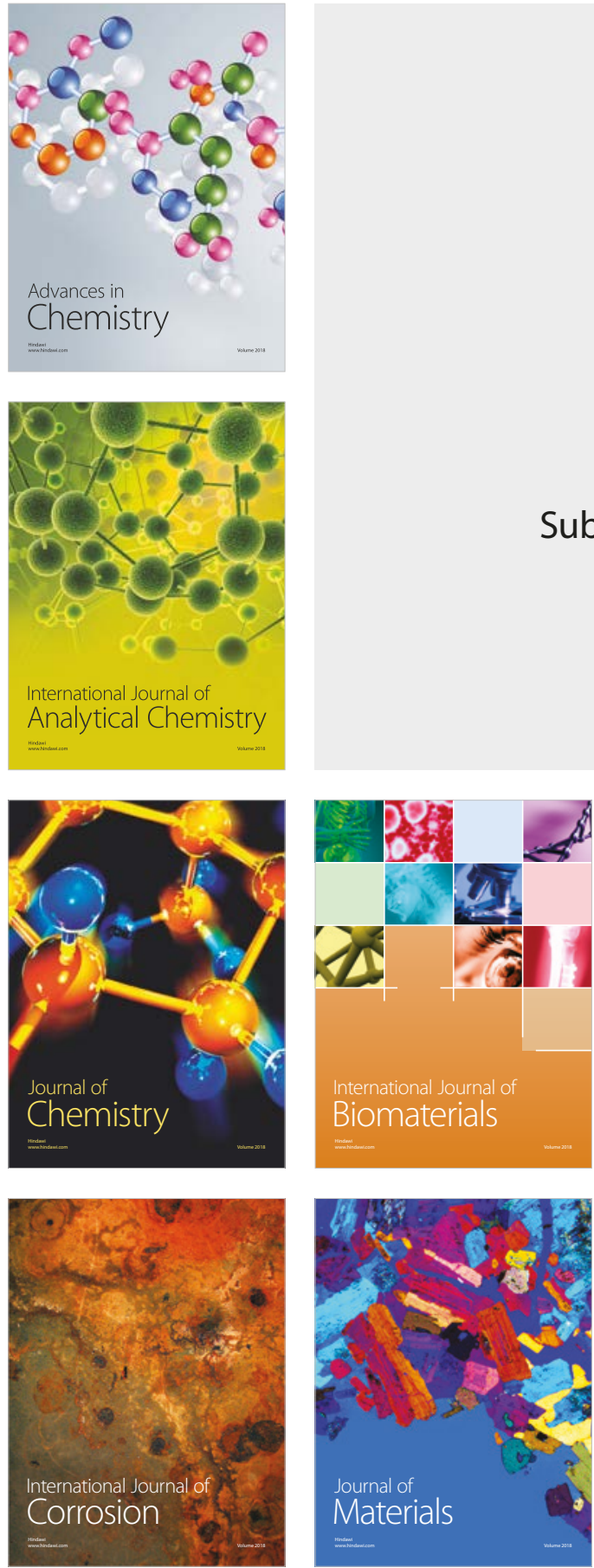

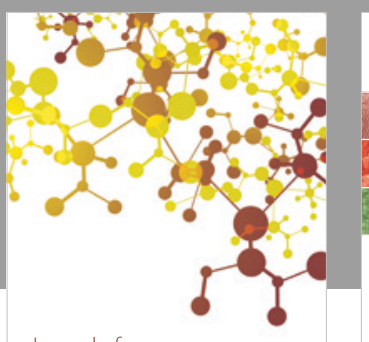

Journal of

Applied Chemistry
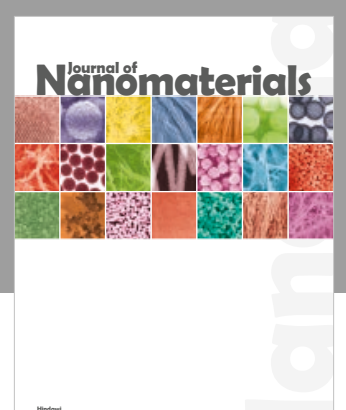

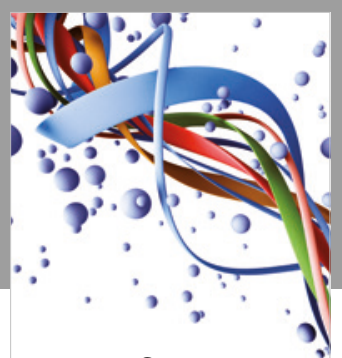

Scientifica

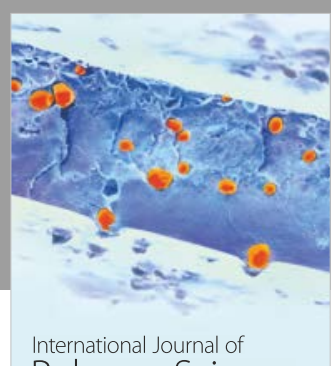

Polymer Science

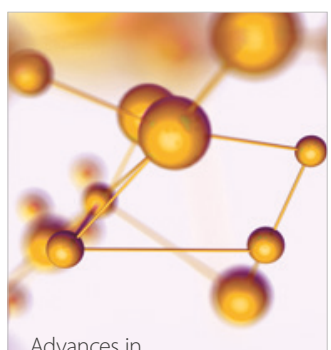

Physical Chemistry
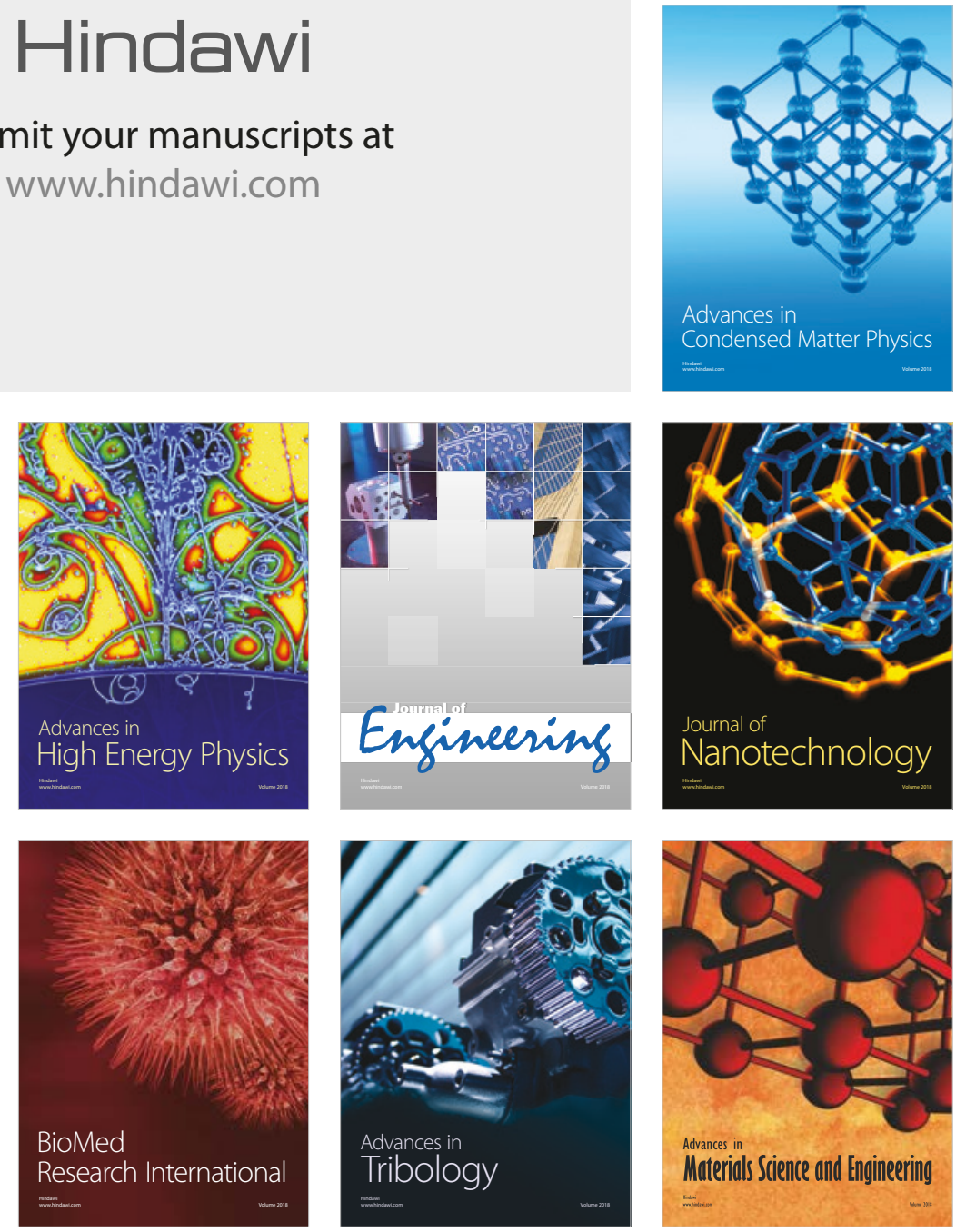